\title{
Brainstem Application of Melanocortin Receptor Ligands Produces Long-Lasting Effects on Feeding and Body Weight
}

\author{
Harvey J. Grill, ${ }^{1}$ Abigail B. Ginsberg, ${ }^{1}$ Randy J. Seeley, ${ }^{2}$ and Joel M. Kaplan ${ }^{1}$ \\ ${ }^{1}$ Department of Psychology and Institute of Neurological Sciences, University of Pennsylvania, Philadelphia, Pennsylvania \\ 19104, and 2Department of Psychiatry, University of Cincinnati, Cincinnati, Ohio 45267
}

\begin{abstract}
Recent evidence suggests that the central melanocortin (MC) system is a prominent contributor to food intake and body weight control. MC receptor (MC-R) populations in the arcuate and paraventricular nuclei are considered probable sites of action mediating the orexigenic effects of systemically or intracerebroventricularly administered ligands. Yet, the highest MC4-R density in the brain is found in the dorsal motor nucleus of the vagus nerve, situated subjacent to the commissural nucleus of the solitary tract, a site of pro-opiomelanocortin mRNA expression. We evaluated the contribution of the caudal brainstem MC system by (1) performing respective doseresponse analyses for an MC-R agonist (MTII) and antagonist (SHU9119) delivered to the fourth ventricle, (2) comparing, in the same rats, the fourth intracerebroventricular dose-response profiles to those obtained with lateral intracerebroventricular delivery, and (3) delivering an effective dose of MTII or SHU9119 to rats before a $24 \mathrm{hr}$ period of food deprivation. Fourth intra-
\end{abstract}

The central melanocortin (MC) system has rapidly become a focus of attention in the area of food intake and body weight control. The MC 4 receptor (MC4-R) knock-out mouse is obese, hyperinsulinemic, and hyperphagic (Huszar et al., 1997), as is the agouti mouse, which chronically produces an ectopic protein that acts as a competitive antagonist of the MC4-R (Lu et al., 1994). Administration of the MC3/4-R agonist MTII into the forebrain ventricles of rats and mice produces a dose-related suppression of food intake (Fan et al., 1997; Thiele et al., 1998) and body weight (Thiele et al., 1998). In mice, lateral intracerebroventricular delivery of the MC4/3-R antagonist SHU9119 (Hruby et al., 1995) stimulates feeding and reverses the intake-suppressive effects of MTII (Fan et al., 1997). Effects of intracerebroventricular leptin administration on food intake and body weight in the rat (Campfield et al., 1996; Brunner et al., 1997) are reversed by intracerebroventricular injection of SHU9119 (Seeley et al., 1997). Moreover, leptin treatment elevates hypothalamic proopiomelanocortin (POMC) mRNA expression (Schwartz et al., 1997; Mizuno et al., 1998). The latter results suggest that melanocortin signaling plays an integral role in the action of leptin on energy homeostasis.

Of the central elements of the MC system that may contribute to intake control, only those in the hypothalamus have been

\footnotetext{
Received July 6, 1998; revised Sept. 11, 1998; accepted Sept. 15, 1998.

This study was supported by National Institutes of Health Grants DK-21397 and DK-54080. We thank Keith Yagaloff and Paul Burn (Hoffmann-La Roche, Nutley, NJ) for their generous gift of MTII and SHU9119.

Correspondence should be addressed to H. Grill, University of Pennsylvania, 3815 Walnut Street, Philadelphia, PA 19104.

Copyright (C) 1998 Society for Neuroscience $\quad 0270-6474 / 98 / 1810128-08 \$ 05.00 / 0$
}

cerebroventricular agonist treatment yielded a dose-dependent reduction of short-term ( 2 and $4 \mathrm{hr}$ ) and longer-term (24 hr) food intake and body weight. Fourth intracerebroventricular antagonist treatment produced the opposite pattern of results: doserelated increases in food intake and corresponding increases in body weight change for the $24-96 \mathrm{hr}$ observation period. Comparable dose-response functions for food intake and body weight were observed when these compounds were delivered to the lateral ventricle. Results from deprived rats (no effect of MTII or SHU9119 on weight loss) support the impression derived from the dose-response analyses that the body weight change that follows MC treatments is secondary to their respective effects on food intake. Results support the relevance of the brainstem MC-R complement to the control of feeding.

Key words: fourth ventricle; lateral ventricle; food intake; water intake; MTII; SHU9119; dorsal motor nucleus; caudal brainstem; POMC; arcuate nucleus; solitary nucleus considered. Special emphasis has been placed on the POMC neurons in the arcuate nucleus, which produce melanocortins, the endogenous ligands for MC3/4-R (Adan et al., 1994). MC3/4-R populations in the arcuate and paraventricular nuclei are considered probable sites of action mediating the orexigenic effects of systemically or intracerebroventricularly administered MC ligands (Roselli-Rehfuss et al., 1993; Mountjoy et al., 1994; Fan et al., 1997; Mizuno et al., 1998; Thiele et al., 1998). It would appear premature, however, to rule out the potential contribution of the caudal brainstem (CBS) portion of the melanocortin system. There are only two central sites of recognized POMC mRNA expression: the arcuate nucleus and the commissural nucleus of the solitary tract (cNST) in the CBS (Palkovits et al., 1987; Bronstein et al., 1992). The dorsal motor nucleus of the vagus nerve (DMX), immediately subjacent to the cNST, contains the highest MC4-R density found in the brain (Mountjoy et al., 1994). This receptor population has attracted the attention of cardiovascular physiologists ( $\mathrm{Li}$ et al., 1996) but has yet to be explored for a role in energy homeostasis. This is surprising because of the clear feeding relevance of the DMX, NST, and related CBS structures (Ritter et al., 1981; Hyde and Miselis, 1983; Berthoud and Powley, 1985; Flynn and Grill, 1985; Grill and Kaplan, 1990; Calingasan and Ritter, 1993; Fraser et al., 1995; Grill et al., 1997; Kaplan et al., 1998).

The contribution of MC receptors in the caudal brainstem to intake and body weight control is explored in the present study. First, we perform dose-response analyses for MTII and SHU9119 delivered to the fourth ventricle. Second, we compare, in the same rats, the fourth intracerebroventricular dose- 
response profile for the two agents to that obtained with lateral intracerebroventricular delivery. Treatments are evaluated for their short-term (up to $4 \mathrm{hr}$ ) effects on pelleted food and water intake and for their longer-lasting effects (24-96 hr) on food intake and body weight. Third, to determine whether body weight change is secondary to the effects of either agent on food intake or whether, as is apparently with leptin (Hwa et al., 1996; Levin et al., 1996), intake effects do not completely account for changes in body weight, we deliver a suprathreshold dose of MTII or SHU9119 to rats whose food is yoked to that of controls by withholding food for $24 \mathrm{hr}$ after treatment.

\section{MATERIALS AND METHODS}

\section{Subjects}

Male Sprague Dawley rats (Charles River Laboratories, Wilmington, MA), weighing 350-375 gm at the time of surgery, were housed and tested in hanging metal cages. Separate groups of rats, naive unless otherwise noted, were run in each experiment. Rats were maintained on a $12 \mathrm{hr}$ light/dark schedule, with lights off at 12:00 P.M. For experiments 1 and 2, pelleted food and water were available ad libitum. For experiment 3, food, but not water, was withheld for $24 \mathrm{hr}$ after intracerebroventricular injection and returned thereafter. The experimental protocols used conform to institutional standards for animal care.

\section{Surgery}

Rats were anesthetized with a mixture of ketamine $(9 \mathrm{mg} / \mathrm{kg})$ and xylazine ( $1.5 \mathrm{mg} / \mathrm{kg}$, i.m.). A 22-ga intracerebroventricular guide cannula (PlasticsOne) was positioned stereotaxically above the fourth ventricle (on the midline, $2.5 \mathrm{~mm}$ anterior to the occipital suture, $4.5 \mathrm{~mm}$ below dura, $2.0 \mathrm{~mm}$ above injection site), and another cannula was positioned above the lateral ventricle $(0.9 \mathrm{~mm}$ posterior to bregma, $1.6 \mathrm{~mm}$ lateral to midline, $2.0 \mathrm{~mm}$ below the dura, $2 \mathrm{~mm}$ above the injection site). The two guide cannulas were cemented to jewelers screws attached to the skull. Obturators were inserted into the guide cannula. Rats recovered for a minimum of $7 \mathrm{~d}$, during which they were handled, and daily food, water, and body weight measurements were taken.

\section{Procedures}

Injections. MTII and SHU9119 were gifts of Keith Yagaloff and Paul Burn (Hoffmann-La Roche, Nutley, NJ). Doses were prepared using sterile isotonic saline and kept frozen at $-80^{\circ} \mathrm{C}$ until use. The 28 -ga injector, when inserted, extended $2 \mathrm{~mm}$ beyond the tip of the guide cannula. A $3 \mu \mathrm{l}$ volume was loaded into a Hamilton microsyringe and was injected over a $4 \mathrm{~min}$ period. The injector was withdrawn $1 \mathrm{~min}$ later. Average latency from injection to lights out was $30 \mathrm{~min}$. Rats received access to preweighed food and water at the onset of lights out.

Verification of cannula placement. Placement of each intracerebroventricular cannula was functionally evaluated before testing by measurement of the rise in plasma glucose after injection of $210 \mu \mathrm{g}$ of 5-thio-Dglucose in $3 \mu \mathrm{l}$ of isotonic saline. [This sympathoadrenal response triggered by intracerebroventricular infusion has been described previously (Ritter et al., 1981; Flynn and Grill, 1985).] Only rats that responded with at least a doubling of plasma glucose after 5-thio-D-glucose injection were used in experiments 1-3.

Measurement of food, water, and body weight. One hour before lights out, the food hopper and water bottle were removed and weighed, and daily food and water intake values were determined. At this time, rats were removed from their cages, weighed, and returned to their cages. A fresh supply of preweighed food and water was returned $1 \mathrm{hr}$ later, at the onset of lights out. Food intake was calculated by subtracting the weight of the hopper from its initial weight and adding the weight of crumbs collected from under each cage. Water intake was determined by subtracting the volume of the bottle from its initial volume. On injection days, food and water intake was also determined at 2 and $4 \mathrm{hr}$ after lights out.

\section{Experimental Design}

Experiment 1. A dose-response analysis for MTII (vehicle, 0.01, 0.1, and $1.0 \mathrm{nmol}$ ) was composed for fourth and lateral ventricle placements in the same rats $(n=10)$. All rats were tested once under each of the eight injection conditions ( 2 cannulas $\times 4$ doses), with testing order counterbalanced across rats. Injection conditions were separated by $72 \mathrm{hr}$. Doses

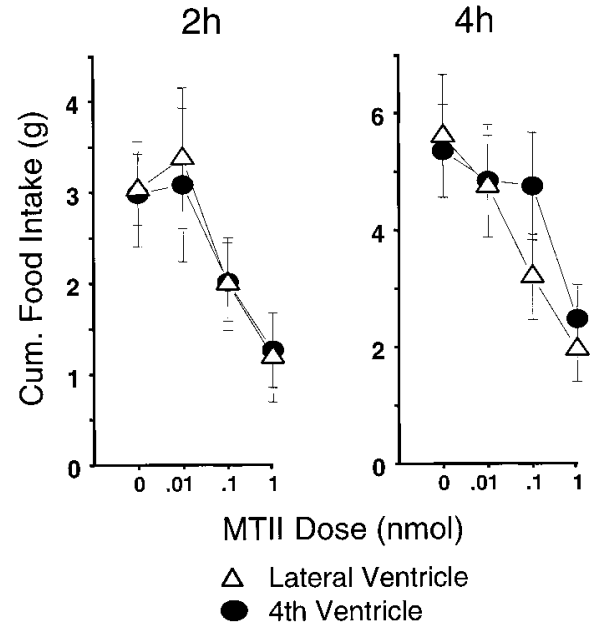

Figure 1. MTII dose-related food consumption (in grams) for the $2 \mathrm{hr}$ or cumulative $4 \mathrm{hr}$ period beginning with lights out. Lateral or fourth intracerebroventricular injections were delivered $30 \mathrm{~min}$ before lights out.

were taken from the available literature (Fan et al., 1997; Thiele et al., 1998).

Experiment 2. A dose-response analysis for SHU9119 (vehicle, 0.25 , 0.50 , and $1.0 \mathrm{nmol}$ ) was composed for fourth and lateral intracerebroventricular placements $(n=8)$. The same design described for experiment 1 was used, except that $96 \mathrm{hr}$ separated injection conditions.

Experiment 3. Rats $(n=9$, run previously in experiment 1$)$ received suprathreshold doses of SHU9119 $(0.5 \mathrm{nmol})$ and MTII $(1.0 \mathrm{nmol})$, and their respective vehicle controls were delivered to the fourth ventricle. Food was withheld for $24 \mathrm{hr}$ after intracerebroventricular injection; water was available at all times. The interinjection interval was the same as that used for experiments 1 and 2: $72 \mathrm{hr}$ for MTII and its vehicle, and $96 \mathrm{hr}$ for SHU9119 and its vehicle. Condition testing order was counterbalanced across rats.

\section{Statistical analyses}

Results for experiments 1 and 2 were analyzed via a two-way (cannula placement $\times$ dose) repeated-measures ANOVA. The four conditions of experiment 3 were treated as levels of a one-way repeated-measures ANOVA. Post hoc comparisons were performed via an LSD test.

\section{RESULTS}

\section{Experiment 1: MTII dose-response analysis}

MTII yielded a dose-dependent inhibition of short- and longerterm food intake. The response functions obtained from the two intracerebroventricular administration sites were indistinguishable, except for that seen for water intake over the short-term.

Figure 1 shows the $2 \mathrm{hr}$ and cumulative $4 \mathrm{hr}$ food intakes (mean + SEM), both of which varied as a function of dose $\left(F_{(3,27)}=\right.$ $8.23 ; p<0.005 ; F_{(3,27)}=10.27 ; p<0.001$, respectively) but not of cannula placement $(F<1.00, \mathrm{NS})$. For both time points, significant food intake suppression against vehicle baseline was obtained with the 0.1 and $1.0 \mathrm{nmol}$ doses $(p<0.015)$. There were no significant interactions between dose and cannula placement.

As shown in Figure 2, top row, left, the food intake-suppressive effects of MTII dose were strongly expressed in the $24 \mathrm{hr}$ measure $\left(F_{(3,27)}=27.10 ; p<0.00001\right)$. Post hoc analyses showed significant effects for the 0.1 and $1.0 \mathrm{nmol}$ doses, evaluated against vehicle baseline. For $24 \mathrm{hr}$ intake, as for the short-term measures, there was no main effect of cannula placement $\left(F_{(1,9)}=0.09, \mathrm{NS}\right)$ and no significant two-factor interaction. Daily (noncumulative) intake readings 48 and $72 \mathrm{hr}$ after injection (Fig. 2, top row, middle and right $)$ did not vary with dose $\left(F_{(3,27)}=1.16\right.$, NS; $F_{(3,27)}=1.51$, $\mathrm{NS}$, respectively) or with cannula placement $\left(F_{(1,9)}=1.51\right.$, NS; 


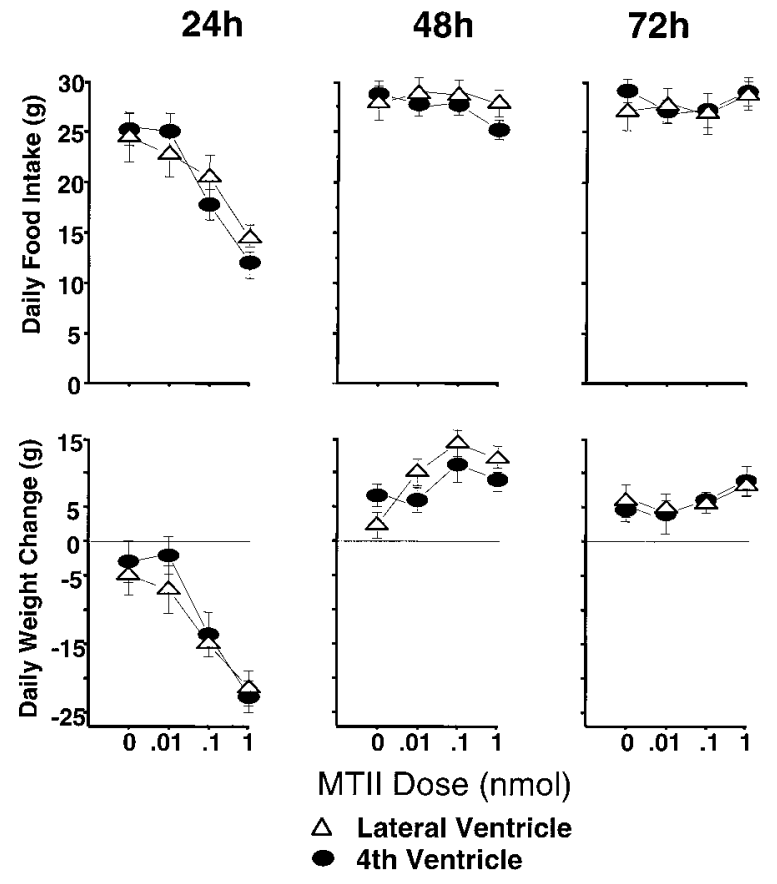

Figure 2. Daily MTII dose-related food consumption (in grams) for the $3 \mathrm{~d}$ after a single intracerebroventricular injection (top). Daily change in body weight (in grams) for the same period after MTII treatment (bottom).

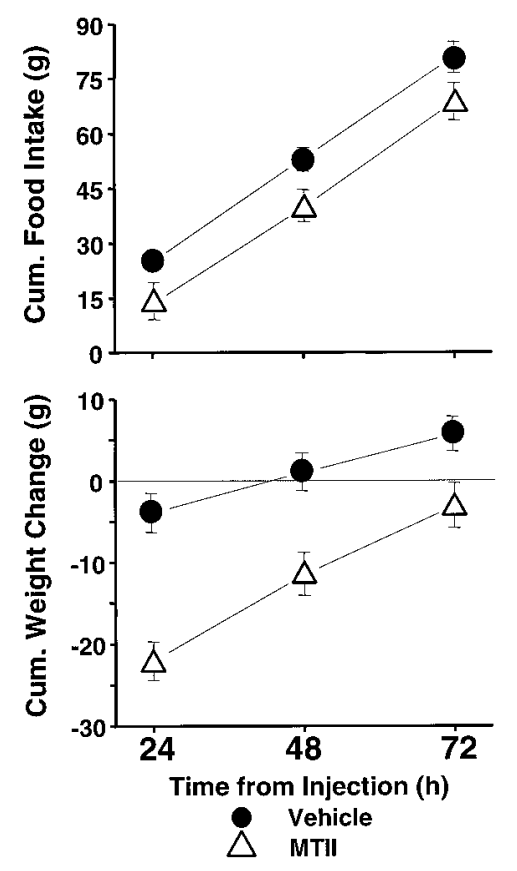

Figure 3. Cumulative food intake (top) and cumulative body weight change (bottom) after delivery of $1.0 \mathrm{nmol}$ MTII or vehicle to the fourth ventricle.

$F_{(1,9)}=0.22$, NS, respectively); the interaction terms also were not significant. Because of this lack of drug effect on these latter daily intake measures, the effect obtained for the first $24 \mathrm{hr}$ was carried forward into significantly suppressed cumulative intakes 48 and $72 \mathrm{hr}$ after injection. This result is illustrated in Figure 3, top, which shows cumulative food intakes for the $1 \mathrm{nmol}$ dose against vehicle delivered to the fourth ventricle.

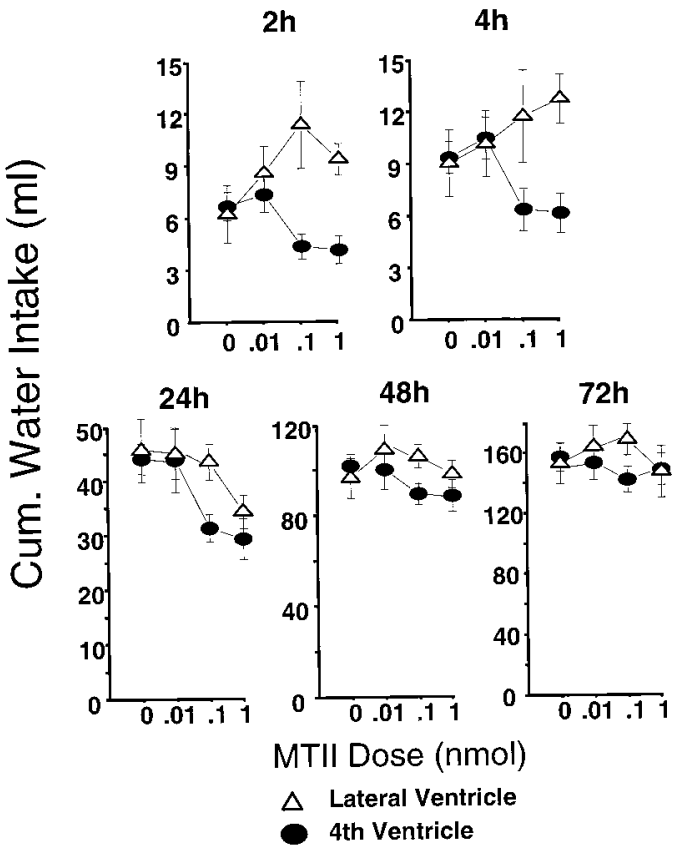

Figure 4. Cumulative water intake for the $2-72 \mathrm{hr}$ period after intracerebroventricular delivery of MTII.

Figure 2, bottom row, shows the changes in daily (noncumulative) body weight after MTII treatment. Body weight $24 \mathrm{hr}$ after injection was significantly reduced as a function of MTII dose $\left(F_{(3,24)}=38.6 ; p<0.00001\right)$, with no significant cannula placement effect $(F<1, \mathrm{NS})$ and no two-factor interaction. Despite no effect of the drug on intake between 24 and $48 \mathrm{hr}$ after injection, body weight for the same period significantly increased as a function of MTII dose $\left(F_{(3,24)}=11.3 ; p<0.00008\right)$. There was a trend toward a further dose-related increase in body weight between 48 and $72 \mathrm{hr}$ (Fig. 2, bottom row, right) that was not, however, statistically reliable. (There were no significant cannula placement effects or two-factor interactions for these periods.) The body weight increases between 24 and $72 \mathrm{hr}$ after injection ameliorated the acute weight loss observed over the first $24 \mathrm{hr}$ after injection. For the lowest effective dose $(0.1 \mathrm{nmol})$, the recovery of weight initially lost was such that 48 and $72 \mathrm{hr}$ after injection, there was no significant net body weight change relative to vehicle conditions. The body weight recovery was not complete for the $1.0 \mathrm{nmol}$ dose (Fig. 3, bottom), however, because cumulative body weight loss, relative to vehicle, remained significant 48 and $72 \mathrm{hr}$ after treatment $(p<0.0001)$ (Fig. 3, bottom).

As can be seen in Figure 4, top row, the effects of MTII on short-term water intake were dramatically different for the two intracerebroventricular placements. For both the 2 and $4 \mathrm{hr}$ readings, MTII tended to decrease cumulative water intake when delivered to the fourth ventricle, but when delivered to the lateral ventricle, MTII increased water intake. This impression is underscored by significant dose $\times$ ventricle interactions $\left(F_{(3,24)}=4.17\right.$; $p<0.02 ; F_{(3,24)}=3.24 ; p<0.04$, respectively, for the 2 and $4 \mathrm{hr}$ ANOVAs). The dose-related stimulation of drinking that followed lateral intracerebroventricular injection of MTII does not appear to derive from the osmotic properties of the MTII injection but may relate to the stimulation of MC3-Rs and MC4-Rs on the neurons of several forebrain periventricular nuclei known to participate in the neural control of drinking (Ramsey and Thrasher, 1990; Roselli-Rehfuss et al., 1993). The stimulatory 
$2 \mathrm{~h}$

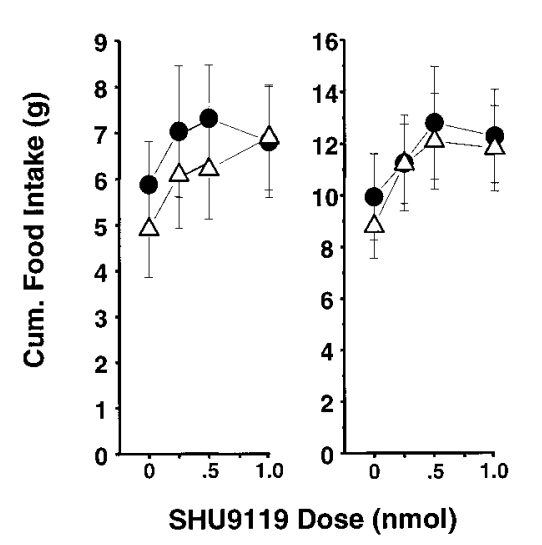

$2 h$

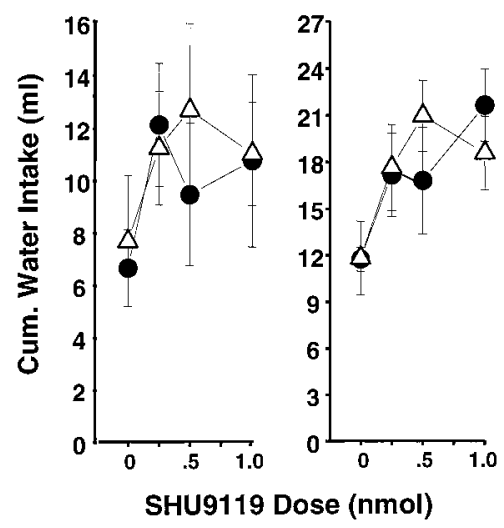

Figure 5. SHU9119 dose-related food (in grams) and water (in milliliters) consumption for the $2 \mathrm{hr}$ or cumulative $4 \mathrm{hr}$ period beginning with lights out. Lateral or fourth intracerebroventricular injections were delivered 30 min before lights out.

effect of MC agonist on drinking is a novel result; in the mouse, lateral intracerebroventricular MTII $(3 \mathrm{nmol})$ reduced short-term water intake (Fan et al., 1997). The injection site disparity in MTII response had disappeared by the $24 \mathrm{hr}$ cumulative water intake reading (Fig. 3, bottom) in which there was an overall suppressive effect of MTII dose $\left(F_{(3,24)}=6.27 ; p<0.003\right)$ but no ventricle effect $\left(F_{(1,8)}=2.42\right.$, NS) or two-factor interaction $\left(F_{(3,24)}=1.36, \mathrm{NS}\right)$. The MTII effect was expressed in significant reductions in water intake for the $0.1(p<0.04)$ and $1.0(p<$ $0.002) \mathrm{nmol}$ doses evaluated against vehicle baseline values. For the 48 and $72 \mathrm{hr}$ readings, there were no significant main effects or interactions.

\section{Experiment 2: SHU9119 dose-response analysis}

SHU9119 produced a marginally significant elevation of cumulative food intake for the 2 and $4 \mathrm{hr}$ postinjection readings $\left(F_{(3,21)}\right.$ $=2.75 ; p=0.068 ; F_{(3,21)}=2.69 ; p=0.072$, respectively) (Fig. 5, left $)$ and a significant dose-related elevation of cumulative water intake over the same period $\left(F_{(3,15)}=3.16 ; p=0.055 ; F_{(3,15)}=\right.$ $3.50 ; p<0.05$, respectively) (Fig. 5, right). For these short-term measures, there was no significant effect of cannula placement on food or water intake, nor was there any significant two-factor interaction.

Figure 6, top row, left, shows the substantial dose-related increase in food intake during the $24 \mathrm{hr}$ after SHU9119 injection $\left(F_{(3,21)}=39.0 ; p<0.00001\right)$. The elevation in $24 \mathrm{hr}$ intake was significant (against vehicle baseline) for all doses delivered to either ventricle $(p<0.0005)$. Daily (noncumulative) intake readings taken 48, 72, and $96 \mathrm{hr}$ after injection were each significantly elevated by SHU9119 in a dose-related manner $\left(F_{(3,21)}=17.70\right.$, 10.07 , and 8.49, respectively; $p<0.0007$ ). Post hoc tests showed that the intake value of each dose exceeded that for the vehicle from 24-96 hr, except for the weakest dose at the $96 \mathrm{hr}$ measurement point. Thus, the magnitude of the treatment effect on cumulative intake progressively increased over the 4 postinjection days (Fig. 7, top). There were relatively small but significant main effects of cannula placement for the 24,48 , and $72 \mathrm{hr}$ daily intakes $\left(F_{(1,7)}=8.87,11.29\right.$, and 7.95 , respectively; $\left.p<0.026\right)$, but there were no significant interactions between placement and SHU9119 dose.

Figure 6, bottom row, shows the noncumulative daily body weight changes for the $4 \mathrm{~d}$ after SHU9119 treatment. The $24 \mathrm{hr}$ weights were significantly elevated as a function of dose $\left(F_{(3,21)}=\right.$

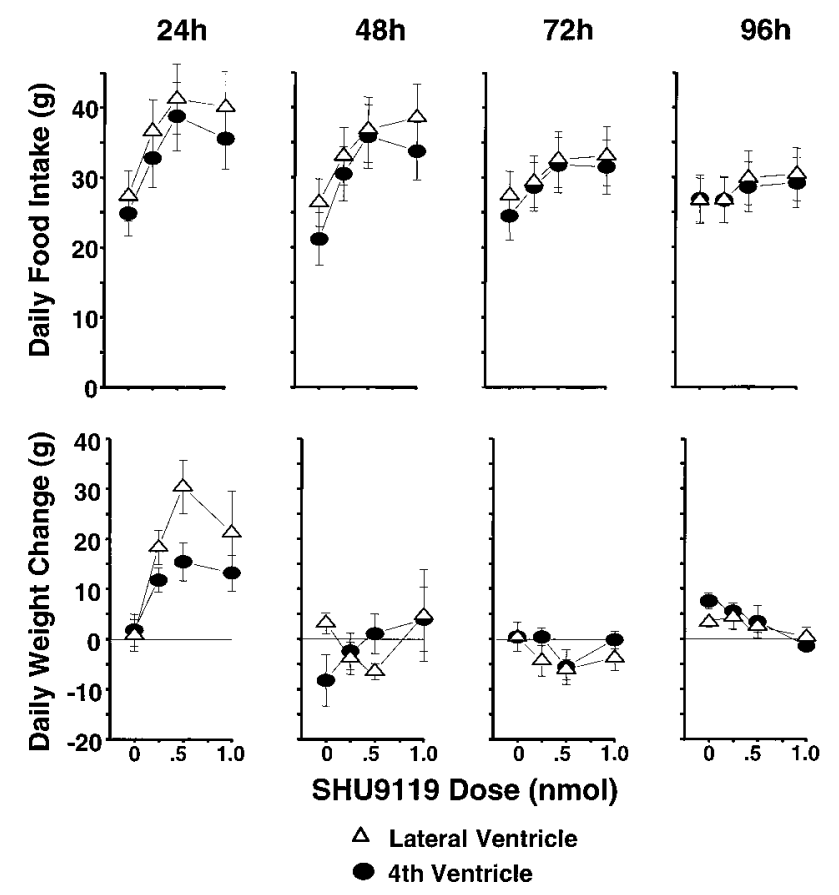

Figure 6. Daily SHU9119 dose-related food consumption (in grams) for the $4 \mathrm{~d}$ after a single intracerebroventricular injection (top). Daily change in body weight (in grams) for the same period after SHU9119 treatment (bottom).

7.33; $p<0.0015)$. The trend toward a greater effect with lateral versus fourth intracerebroventricular administration was marginally significant $\left(F_{(1,7)}=5.28 ; p=0.055\right)$; the two-factor interaction term was not significant. Despite the successive daily increases in food intake, there were no further increments in body weight beyond the first postinjection day. The weight gain over the first $24 \mathrm{hr}$ did carry forward to yield a significant increase in net weight gain $96 \mathrm{hr}$ after injection for each dose relative to vehicle baseline (Fig. 7, bottom, $0.5 \mathrm{nmol}$ result).

Water intake for the $24 \mathrm{hr}$ postinjection period was increased as a function of SHU9119 dose $\left(F_{(3,15)}=17.48 ; p<0.00004\right)$. As was the case for $24 \mathrm{hr}$ pellet intake, the main effect of cannula placement on water intake was significant but small $\left(F_{(1,5)}=\right.$ $23.29 ; p<0.005)$; there was no significant two-factor interaction. 

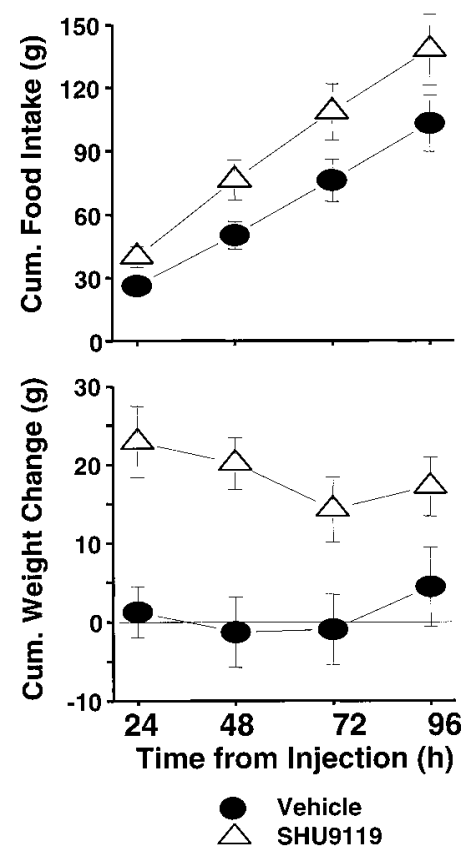

Figure 7. Cumulative food intake (top) and cumulative body weight change (bottom) after delivery of $0.5 \mathrm{nmol}$ of SHU9119 or vehicle to the fourth ventricle.

Daily water intakes between 24 and $96 \mathrm{hr}$ after injection did not vary with either drug dose or cannula placement.

\section{Experiment 3: effects of fourth MTII (1 nmol) and SHU9119 (0.5 nmol) intracerebroventricular injections at the onset of a $\mathbf{2 4} \mathrm{hr}$ period of food deprivation}

Weight loss by the end of the $24 \mathrm{hr}$ deprivation period was not reliably accentuated by MTII or attenuated by SHU9119 (Fig. 8, bottom). The overall one-way ANOVA, with all four injection conditions (SHU9119, MTII, and respective vehicles) as levels, did yield a significant result $\left(F_{(3,24)}=3.09 ; p<0.05\right)$. Post hoc tests, however, showed that $24 \mathrm{hr}$ weight loss for the SHU9119 condition was not significantly different from that of its vehicle control $(p=0.22)$ and that weight loss under MTII did not differ from its control values $(p=0.18)$. Values for the two vehicle conditions also did not differ $(p=0.11)$. Rats lost somewhat more weight under MTII (40.1 gm) than under SHU9119 (36.3 gm), but the difference was not statistically reliable $(p=0.09)$.

There was an overall effect of injection condition on the amount of food ingested during the first $2 \mathrm{hr}$ of refeeding after food deprivation $\left(F_{(3,24)}=4.75 ; p<0.01\right)$. Post hoc tests showed that the effect was carried primarily by significant differences in intake between the MTII condition (mean, $5.34 \mathrm{gm}$ ) and the other three conditions $(p<0.015)$, which did not differ from each other (means: SHU9119, 12.72 gm; vehicle for SHU9119, 12.09 $\mathrm{gm}$; and vehicle for MTII, $11.29 \mathrm{gm}$ ). A comparable pattern of significant results was obtained for cumulative intake over the first $4 \mathrm{hr}$ of refeeding $\left(F_{(3,24)}=9.88 ; p<0.0002\right)$ (means: SHU9119, $17.88 \mathrm{gm}$; vehicle for SHU9119, $18.21 \mathrm{gm}$; MTII, $9.90 \mathrm{gm}$; and vehicle for MTII, $16.14 \mathrm{gm})$.

A significant effect of injection condition was obtained for the amount consumed during the first $24 \mathrm{hr}$ of refeeding (i.e., $48 \mathrm{hr}$ after treatment) $\left(F_{(3,24)}=14.56 ; p<0.00002\right)$ (Fig. 8, top $)$. Food intake for the MTII condition was significantly lower than that for either vehicle condition $(p<0.002)$ and that for the SHU9119
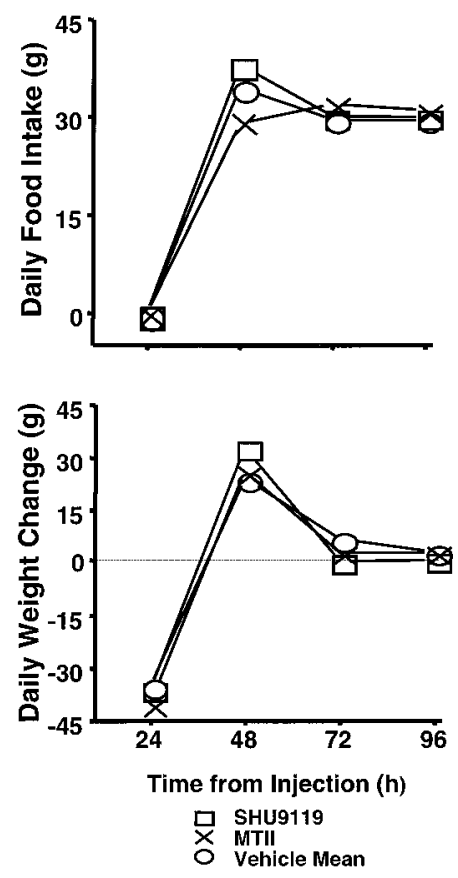

Figure 8 . Daily food intake (top) and body weight change (bottom) up to $96 \mathrm{hr}$ after fourth intracerebroventricular injection [MTII $(1.0 \mathrm{nmol})$, SHU9119 $(0.5 \mathrm{nmol})$, or vehicle] in rats $(n=9)$ that were food-deprived for $24 \mathrm{hr}$ after treatment. There were no significant differences between values obtained for the two vehicle conditions run; values for the vehicle conditions were combined for clarity of presentation.

condition $(p<0.00001)$. Values for the SHU9119 condition were significantly higher than those for both vehicle conditions $(p<$ 0.04). There were no significant effects (overall ANOVA or paired comparisons) on the daily intake readings taken 72 or 96 hr after injection (Fig. 8).

For all four injection conditions, a substantial portion of the weight loss during the deprivation period was recovered during the first day of refeeding (i.e., $24-48 \mathrm{hr}$ after injection). The degree of body weight recovery did vary with injection condition $\left(F_{(3,24}=8.58 ; p<0.0005\right)$. Underlying the effect was a significantly greater rebound for the SHU9119 condition than for the other three conditions $(p<0.03)$ and significantly less recovery for the MTII condition compared with its vehicle control $(p<$ 0.03 ). Figure 8, compare top, bottom, shows that the difference in weight recovery between the MTII and SHU9119 conditions was commensurate with the between-condition difference in amount consumed for the first refeeding day. The differences across conditions in weight recovery over the first refeeding day were made up for during the second (i.e., 48-72 hr after treatment). Thus, there was significantly greater weight gain for the MTII condition and each control condition, relative to that under the SHU9119 condition $(p<0.05)$. By the following day (i.e., 72-96 $\mathrm{hr}$ after treatment), there were no significant between-condition differences in body weight change $\left(F_{(3,24)}=0.16, \mathrm{NS}\right)$ and no differences in net weight change to this point from the time of treatment.

There was an overall effect of injection condition on the amount of water consumed during the first $24 \mathrm{hr}$ after injection $\left(F_{(3,24)}=3.56 ; p<0.03\right)$ when food was unavailable. Post hoc tests, however, showed that the effect was carried primarily by a significant difference in intake between the MTII (mean, 12.1 $\mathrm{gm})$ and SHU9119 (mean, $27.5 \mathrm{gm})$ conditions $(p<0.005)$. 
Water intake under MTII or SHU9119 did not differ from their respective control injection values $(p>0.21)$ for the $24 \mathrm{hr}$ period of food deprivation. Water intake was affected by injection condition during the first refeeding day $\left(F_{(3,24)}=37.49 ; p<0.0006\right)$. During this period, water intake was reduced by MTII and augmented by SHU9119 $(p<0.05)$. Thereafter, there were no effects of treatment on daily water intake $(F<2.21)$.

\section{DISCUSSION}

The effects on food intake and body weight that we report for fourth (brainstem) ventricular injection of MC-R ligands are qualitatively similar to what has been observed for lateral or 3rd (forebrain) ventricular application (Fan et al., 1997; Thiele et al., 1998). Here, we directly compared fourth and lateral intracerebroventricular placements with an integrated design using the same animals and found that the overall sensitivities of the two placements to MTII and SHU9119 were comparable in terms of threshold dose, degree of effect across doses, and duration of effect. For MTII, the dose-response curves for short-term and longer-term effects on food intake, body weight, and water consumption did not significantly differ for the two ventricular placements. For SHU9119, there were no effects of cannula placement on shorter-term treatment outcomes. Although significant placement effects on longer-term response to SHU9119 were noted, the magnitude of the between-ventricle effects on food intake and body weight change were relatively small. There were, moreover, no significant interactions between injection site and SHU9119 dose. The comparable dose-response functions (Figs. 2, 6) for the two ventricles in response to the $\mathrm{MC}$ agonist and antagonist argue strongly that the anatomical perspective on the MC contribution to intake and body weight control should be revised and expanded to include the CBS receptor complement.

Opposite effects on food intake and body weight were obtained with the MC agonist and antagonist for the $24 \mathrm{hr}$ after injection. MTII treatment lowered intake and body weight over this period, whereas SHU9119 yielded increased intake and body weight. For MTII, no effect on intake and body weight was seen beyond this time (experiment 1). For SHU9119, however, a single injection continued to augment daily food intake for the 3 subsequent days examined. The $96 \mathrm{hr}$ duration of the intake facilitatory effect of SHU9119 is the longest yet reported (Fan et al., 1997; Thiele et al., 1998). The opposing effects of MTII and SHU9119 suggest that a broad range of dynamic action on feeding can be mediated by the same or primarily overlapping populations of $\mathrm{MC}$ receptors.

The dose-related intake stimulatory effect of the MC4/3 antagonist SHU9119 seen here and elsewhere (Fan et al., 1997) appears to indicate a contribution of endogenous melanocortin activity to feeding control. POMC peptides ( $\alpha$-MSH, ACTH-49- $\mathrm{NH}_{2}$, and $\gamma-\mathrm{MSH}$ ) are the endogenous ligands for the MC3-R and/or MC4-R (Adan et al., 1994). Food intake is suppressed when exogenous ACTH or $\alpha$-MSH is delivered to the forebrain ventricles (Tsujii and Bray, 1989; Ferrari et al., 1992). Additional support for the hypothesis that endogenous MC activity contributes to intake control comes from recent demonstrations that arcuate nucleus POMC mRNA expression (and presumably levels of intake-inhibitory melanocortins) are reduced by food restriction or deprivation (Brady et al., 1990; Kim et al., 1996; Schwartz et al., 1997; Mizuno et al., 1998). Further, Mizuno et al. (1998) noted that decreases in POMC mRNA are common to a variety of obesity models. Previous discussion of the relevance of endogenous MC contributions to intake control have been limited in focus to the forebrain. The elevation of intake and body weight after fourth intracerebroventricular injection of SHU9119 reported here recommends expanding this discussion to include endogenous MC activity in the CBS.

Inspection of the dose-response data from experiments 1 and 2 provides the impression that the observed changes in body weight were secondary to the respective actions of MTII and SHU9119 on food intake. This impression was reinforced by the results of experiment 3 in which deprivation was used as a yoking strategy, i.e., to equate the intake (at zero) after delivery of the two drugs with otherwise opposite ingestive effects. Any effect on body weight change during the deprivation period could then be ascribed to a primary metabolic action of the MC-R ligand(s). We found, however, that weight loss was not reliably accentuated by MTII or SHU9119 (Fig. 8). During the first refeeding day (24-48 hr after injection), somewhat less weight was recovered after MTII than after SHU9119 treatment. It would appear unlikely that this contrast reflects a delayed metabolic effect(s) of the treatments, because the difference in body weight recovery was commensurate with the between-condition differences in amount ingested during that first refeeding day (Fig. 8). Thus, no evidence of a primary metabolic action of these MC-R ligands was obtained under the present testing paradigm.

The pattern of body weight recovery seen in response to the 24 hr intake-suppressive effect of MTII is consistent with the pattern of body weight recovery observed after $24 \mathrm{hr}$ food deprivation in vehicle-treated rats. In both contexts, body weight recovery proceeded over the ensuing days in the absence of appreciable compensatory feeding. The body weight recovery seen after deprivation is driven by coordinated reductions of energy expenditure (metabolic rate, thermogenesis, and activity) (Rashotte et al., 1995). Similar mechanisms may underlie the recovery of body weight seen after MTII treatment. The pattern of body weight gain and recovery that follows SHU9119 treatment is reminiscent of that seen with the cafeteria feeding model of reversible obesity (Rothwell and Stock, 1979, 1981). In both situations, weight gain was limited despite a persistent hyperphagia. Increases in energy expenditure have been hypothesized to limit weight gain during hyperphagia and the recovery of body weight once cafeteria feeding was discontinued (Rothwell and Stock, 1979). The hyperphagia stimulated by SHU9119 treatment may engage similar compensatory increases in energy expenditure.

Our suggestion that the effects of MC injection on body weight in rats appear secondary to treatment effects on feeding contrasts with judgments about leptin action in the mouse. The indication that the body weight effects of leptin exceed expectations based on intake suppression is derived from work on the ob/ob mouse (Levin et al., 1996). If a similar feeding-independent action of leptin on body weight can be established in the rat, then an interesting tension would arise given current views about the MC mediation of leptin effects (e.g., Mizuno et al., 1998). It is possible that MC may in part mediate leptin effects on intake but that a separate mechanism mediates the potential influence of leptin on metabolic rate.

Single injections of the MC-R ligands in ad libitum fed rats had long-term intake effects that were altered by food deprivation. In the dose-response studies (experiments 1 and 2), intake effects of SHU9119 persisted for $96 \mathrm{hr}$, whereas the effects of MTII lasted $24 \mathrm{hr}$. Deprivation prolonged the effect of MTII effect but shortened that of SHU9119. When food was withheld for $24 \mathrm{hr}$ after injection, the intake-suppressive effect of MTII extended to $48 \mathrm{hr}$ after injection, the period of the first refeeding day (24-48 hr). 
The facilitatory effect of SHU9119 was evident on the first refeeding day (24-48 hr) but not thereafter. The basis for the interaction between physiological state and the longevity of MC ligand action is a matter of speculation. We lack information about when the interaction takes place over a $24 \mathrm{hr}$ deprivation period. We expect that it is unlikely that these ligands continue to act at a given location for a substantial length of time. Therefore, we must also acknowledge a lack of information about other neurochemical systems and perhaps peripheral control systems that support the longer-term effects of these agents. The latter issue, of course, represents a gap in our understanding about how, in nondeprived rats, MTII effects $24 \mathrm{hr}$ intake and particularly how intake is affected up to $96 \mathrm{hr}$ after a single injection of SHU9119.

The evidence presented suggests that there are at least two MC-R populations that can mediate food intake effects of MC ligand treatments. We think it unlikely, despite the caudal flow of $\mathrm{CSF}$, that lateral intracerebroventricular effects are mediated exclusively by CBS MC-Rs. If this were the case, we would expect the dose-effect curve for lateral intracerebroventricular injection to be shifted to the right of that obtained with fourth intracerebroventricular application (Ladenheim and Ritter, 1988). Conversely, it would appear unlikely that the response to fourth intracerebroventricular injection is mediated exclusively by forebrain MC-Rs. First, india ink injected through the fourth intracerebroventricular cannula is not seen rostral to the CBS after death (Flynn and Grill, 1985; Grill et al., 1997). We can also note the example of angiotensin II, with a forebrain receptor substrate for the drinking response, which even at high doses is ineffective when delivered to the fourth ventricle (Fitzsimons and Kucharczyk, 1978). We cannot rule out the possibility that the response to fourth intracerebroventricular injection of these particular MC-R ligands results, in part, from a portion of the infusate reaching forebrain receptors. The argument that forebrain substrates exclusively mediate the intake response to brainstem delivery would appear untenable, however, given that the fourth intracerebroventricular dose-response curves are not shifted to the right of the respective lateral intracerebroventricular functions. A very compelling indication that fourth and lateral intracerebroventricular injection of MTII stimulates different receptor subpopulations is found in the short-term (2-4 hr) water intake responses described here in which brainstem injection yielded a reduction commensurate with the food intake response, but forebrain injection resulted in a dose-related increase in drinking. Further support for the relevance of brainstem MC-Rs to feeding control could be provided by intraparenchymal injection studies. The intake effect seen with fourth intracerebroventricular application may result from stimulation of the prominent group of MC4-Rs in DMX but could also reflect the contribution of MC4-Rs in other CBS structures, such as NST, parabrachial nucleus, and various nuclei of the reticular formation (Mountjoy et al., 1994) and perhaps MC3-Rs in the raphe and periaqueductal gray (RoselliRehfuss et al., 1993).

Further experiments are required to determine whether the disparate populations of MC-Rs are concurrently stimulated under physiological conditions. Anatomical evidence indicates that $\alpha$-MSH produced by POMC-containing neurons in the arcuate nucleus is found in brainstem, as well as in hypothalamic structures (Palkovits et al., 1987). Changes in peptide release from arcuate POMC neurons (e.g., by deprivation or changes in leptin levels) (Schwartz et al., 1997; Mizuno et al., 1998), then, is one mechanism by which activity at forebrain and brainstem MC-Rs may be coordinated. POMC-containing cells in NST project to the same or overlapping set of brainstem targets but do not appear to give rise to ascending projections to hypothalamic structures (Pilcher and Joseph, 1986; Palkovits et al., 1987). The possibility remains, however, that cNST POMC activation indirectly affects arcuate POMC neurons, which in turn stimulates hypothalamic MC-Rs. In the present study, we explored the consequences of exogenous ligands that targeted sets of receptors that were different or at least partially nonoverlapping. Additional work will be required to explore the implications of a coordinated activation of CBS and hypothalamic MC-Rs, if established as a general rule, for feeding control in the short and longer term. Potentially informative studies may entail application of an MC-R agonist to one (ventricular or parenchymal) location and an antagonist delivered to a different site.

\section{REFERENCES}

Adan RA, Cone RD, Burbach JP, Gispen WH (1994) Differential effects of melanocortin peptides on neural melanocortin receptors. Mol Pharmacol 46:1182-1190.

Berthoud HR, Powley TL (1985) Altered plasma insulin and glucose after obesity-producing bipiperidyl brain lesions. Am J Physiol 248:R46-R53.

Brady LS, Smith MA, Gold PW, Herkenham M (1990) Altered expression of hypothalamic neuropeptide mRNAs in food-restricted and food-deprived rats. Neuroendocrinology 52:441-447.

Bronstein DM, Schafer MK, Watson SJ, Akil H (1992) Evidence that beta-endorphin is synthesized in cells in the nucleus tractus solitarius: detection of POMC mRNA. Brain Res 587:269-275.

Brunner L, Nick HP, Cumin F, Chiesi M, Baum HP, Whitebread S, Stricker-Krongrad A, Levens N (1997) Leptin is a physiologically important regulator of food intake. Int $\mathrm{J}$ Obes Relat Metab Disord 21:1152-1160.

Calingasan NY, Ritter S (1993) Lateral parabrachial subnucleus lesions abolish feeding induced by mercaptoacetate but not by 2-deoxy-Dglucose. Am J Physiol 34:R1168-R1178.

Campfield LA, Smith FJ, Burn P (1996) The OB protein (leptin) pathway - a link between adipose tissue mass and central neural networks. Horm Metab Res 28:619-632.

Fan W, Boston BA, Kesterson RA, Hruby VJ, Cone RD (1997) Role of melanocortinergic neurons in feeding and the agouti obesity syndrome. Nature 385:165-168.

Ferrari F, Pelloni F, Giuliani D (1992) B-HT 920 stimulates feeding and antagonizes anorexia induced by $\mathrm{ACTH}$ and immobilisation. Eur J Pharmacol 210:17-22.

Fitzsimons JT, Kucharczyk J (1978) Drinking and haemodynamic changes induced in the dog by intracranial injection of components of the renin-angiotensin system. J Physiol (Lond) 276:419-434.

Flynn FW, Grill HJ (1985) Fourth ventricular phlorizin dissociates feeding from hyperglycemia in rats. Brain Res 341:331-336.

Fraser KA, Raizada E, Davison JS (1995) Oral-pharyngeal-esophageal and gastric cues contribute to meal-induced c-fos expression. Am J Physiol 268:R223-R230.

Grill HJ, Kaplan JM (1990) Caudal brainstem participates in the distributed neural control of feeding. In: Handbook of behavioral neurobiology, Vol 10 (Stricker EM, ed), pp 125-149. New York: Plenum.

Grill HJ, Donahey JCK, King L, Kaplan JM (1997) Contribution of caudal brainstem to D-fenfluramine anorexia. Psychopharmacology 130:375-381.

Hruby VJ, Lu D, Sharma SD, Castrucci AL, Kesterson RA, al-Obeidi FA, Hadley ME, Cone RD (1995) Cyclic lactam alpha-melanotropin analogues of Ac-Nle4-cyclo[Asp5, D-Phe7,Lys10] alpha-melanocytestimulating hormone-(4-10)-NH2 with bulky aromatic amino acids at position 7 show high antagonist potency and selectivity at specific melanocortin receptors. J Med Chem 38:3454-3461.

Huszar D, Lynch CA, Fairchild-Huntress V, Dunmore JH, Fang Q, Berkemeier, LR, Gu W, Kesterson RA, Boston BA, Cone RD, Smith FJ, Campfield LA, Burn P, Lee F (1997) Targeted disruption of the melanocortin-4 receptor results in obesity in mice. Cell 88:131-141.

Hwa JJ, Ghibaudi L, Compton D, Fawzi AB, Strader CD (1996) Intracerebroventricular injection of leptin increases thermogenesis and mobilizes fat metabolism in ob/ob mice. Horm Metab Res 28:659-663. 
Hyde TM, Miselis RR (1983) Effects of area postrema/caudal medial nucleus of solitary tract lesions on food intake and body weight. Am J Physiol 244:R577-R587.

Kaplan JM, Song S, Grill HJ (1998) Serotonin receptors in the caudal brainstem are necessary and sufficient for the anoretic effect of peripherally administered mCPP. Psychopharmacology 137:43-49.

Kim EM, Welch CC, Grace MK, Billington CJ, Levine AS (1996) Chronic food restriction and acute food deprivation decrease mRNA levels of opioid peptides in arcuate nucleus. Am J Physiol 270:R1019-R1024.

Ladenheim EE, Ritter RC (1988) Low-dose fourth ventricular bombesin selectively suppresses food intake. Am J Physiol 255:R988-R993.

Levin N, Nelson C, Gurney A, Vandlen R, de Sauvage F (1996) Decreased food intake does not completely account for adiposity reduction after ob protein infusion. Proc Natl Acad Sci USA 93:1726-1730.

Li SJ, Varga K, Archer P, Hruby VJ, Sharma SD, Kesterson RA, Cone RD, Kunos G (1996) Melanocortin antagonists define two distinct pathways of cardiovascular control by alpha- and gamma-melanocytestimulating hormones. J Neurosci 16:5182-5188.

Lu D, Willard D, Patel IR, Kadwell S, Overton L, Kost T, Luther M, Chen W, Woychik RP, Wilkison WO, Cone RD (1994) Agouti protein is an antagonist of the melanocyte-stimulating-hormone receptor. Nature 371:799-802.

Mizuno TM, Kleopoulos SP, Bergen HT, Roberts JL, Priest CA, Mobbs CV (1998) Hypothalamic pro-opiomelanocortin mRNA is reduced by fasting in $\mathrm{ob} / \mathrm{ob}$ and $\mathrm{db} / \mathrm{db}$ mice, but is stimulated by leptin. Diabetes 47:294-297.

Mountjoy KG, Mortrud MT, Low MJ, Simerly RB, Cone RD (1994) Localization of the melanocortin-4 receptor (MC4-R) in neuroendocrine and autonomic control circuits in the brain. Mol Endocrinol 8:1298-1308.

Palkovits M, Mezey E, Eskay RL (1987) Pro-opiomelanocortin-derived peptides (ACTH/beta-endorphin/alpha-MSH) in brainstem baroreceptor areas of the rat. Brain Res 436:323-338.

Pilcher WH, Joseph SA (1986) Differential sensitivity of hypothalamic and medullary opiocortin and tyrosine hydroxylase neurons to the neurotoxic effects of monosodium glutamate (MSG). Peptides 7:783-789.

Ramsey DJ, Thrasher TN (1990) Thirst and water balance. In: Neurobiology of food and fluid intake (Stricker EM, ed), pp 353-386. New York: Plenum.

Rashotte ME, Basco PS, Henderson RP (1995) Daily cycles in body temperature, metabolic rate, and substrate utilization in pigeons: influence of amount and timing of food consumption. Physiol Behav 57:731-746.

Ritter RC, Slusser PG, Stone S (1981) Glucoreceptors controlling feeding and blood glucose: location in the hindbrain. Science 213:451-453.

Roselli-Rehfuss L, Mountjoy KG, Robbins LS, Mortrud MT, Low MJ, Tatro JB, Entwistle ML, Simerly RB, Cone RD (1993) Identification of a receptor for gamma melanotropin and other proopiomelanocortin peptides in the hypothalamus and limbic system. Proc Natl Acad Sci USA 90:8856-8860.

Rothwell NJ, Stock MJ (1979) Regulation of energy balance in two models of reversible obesity in the rat. J Comp Physiol Psychol 93:1024-1034.

Rothwell NJ, Stock MJ (1981) Regulation of energy balance. Annu Rev Nutr 1:235-256.

Schwartz MW, Seeley RJ, Woods SC, Weigle DS, Campfield LA, Burn P, Baskin DG (1997) Leptin increases hypothalamic pro-opiomelanocortin mRNA expression in the rostral arcuate nucleus. Diabetes 46:2119-2123.

Seeley RJ, Yagaloff KA, Fisher SL, Burn P, Thiele TE, van Dijk G, Baskin DG, Schwartz MW (1997) Melanocortin receptors in leptin effects. Nature 390:349.

Thiele TE, van Dijk G, Yagaloff KA, Fisher SL, Schwartz M, Burn P, Seeley RJ (1998) Central infusion of melanocortin agonist MTII in rats: assessment of c-Fos expression and taste aversion. Am J Physiol 274:R248-R254.

Tsujii S, Bray GA (1989) Acetylation alters the feeding response to MSH and beta-endorphin. Brain Res Bull 23:165-169. 